\title{
CENSURA NO REGIME MILITAR E MILITARIZAÇÃO DAS ARTES
}

\section{Censorship in the military regime and the militarization of arts, from Alexandre Stephanou}

\author{
Miliandre Garcia*
}

\begin{abstract}
STEPHANOU, Alexandre Ayub. Censura no regime militar e militarização das artes. Porto Alegre: Edipucrs, 2001. 328 p. (Coleção História, 44).
\end{abstract}

"Qual de nós, no momento presente, não preferiria, a todos os jornais de 1938 ou 1939, ter nas mãos alguns documentos secretos de chancelaria, alguns relatórios confidenciais de chefes militares?"1

Nos últimos anos, a censura exercida pelo Estado brasileiro nos anos de 1960 e 1970 tem se transformado em objeto de pesquisa para inúmeros pesquisadores das áreas de Ciências Humanas e Artes. Entre as pesquisas acadêmicas mais recentes, podemos incluir Censura no regime militar e militarização das artes, de Alexandre Ayub Stephanou.

O livro, que resultou de uma dissertação de mestrado apresentada no Programa de Pós-Graduação em História da Pontifícia Universidade Católica do Rio Grande do Sul, defende a tese de que a censura no período de 1964 a 1968 não foi "assistemática e eventual”, mas “constante, violenta, desmanteladora e multifacetada” (p. 14), atingindo sobretudo as produções artístico-culturais (p. 291).

Para fundamentar essa tese central, Stephanou não recorreu à documentação produzida pelos órgãos responsáveis pela censura no regime

* Doutoranda em História da Universidade Federal do Rio de Janeiro.

1 BLOCH, Marc. Introdução à história. Tradução: Maria Manuel e Rui Gracio. 3. ed. Lisboa: Europa-América, 1976. 181 p. 58. 
militar, mas elegeu, como fonte historiográfica, duas revistas de grande circulação nacional nas décadas de 1960 e 1970: a Revista Civilização Brasileira (RCB), que editou 22 números entre 1965 e 1968; e a Veja, que publicou o primeiro número em 11 de setembro de 1968. O autor justifica que a "Veja foi escolhida pelo seu caráter de grande imprensa, de pretensa neutralidade, enquanto a Revista Civilização Brasileira era claramente posicionada contra o Regime vigente” (p. 17).

A indagação de Bloch transcrita propositalmente como epígrafe não objetiva determinar uma escala hierárquica das fontes ou então induzir que algumas são mais legítimas do que outras. Acontece que, apesar de não existirem documentos menos ou mais verdadeiros, estes devem corresponder, de alguma forma, à problemática da pesquisa. Parece uma hipótese difícil esta de investigar a censura a partir de uma revista como a RCB - que nunca foi censurada e que é assumidamente de esquerda. Ou, ainda, afirmar que a censura exercida pelo regime militar no período de 1964 e 1968 foi “constante e sistemática” (p. 306) baseando-se na revista Veja, que só foi lançada no período posterior ao delimitado pelo autor, isto é, no final de 1968.

Essa escolha e, posteriormente, a apreensão das fontes por Stephanou influenciaram na abordagem da censura e das produções artístico-culturais da época, desenvolvida nas quatro partes que compõem o livro: na apresentação da história e conceito da censura (parte I), na síntese do contexto político, econômico, social (parte II), artístico e cultural (parte III) e na argumentação da tese central (parte IV).

Na primeira parte - Censura: história e teoria -, o autor apresenta a história da censura no Brasil desde o século XVIII e acentua as especificidades da censura no regime militar, que - mesmo compondo "um fenômeno universal e atemporal” (p. 25) - foi, nos anos de 1960 e 1970, “institucionalizada, sistematizada, materializada e explicitada” (p. 26).

Vê-se então que uma das principais críticas de Stephanou à censura exercida pelo Estado militarizado é a de intervir no direito à informação produzida e transmitida pelos meios de comunicação, sobretudo pela imprensa. Não obstante, ao contrário da argumentação criteriosa apresentada no capítulo Imprensa e realidade (p. 43-46), o autor procede com uma argumentação que consagra esses mesmos meios de comunicação (p. 11; 27-28; 36-38), como se a censura, e somente ela, impedisse assim o que ele chama de compreensão do todo e da vida social (p. 11; 28). Então, segundo Stephanou, "a supressão do direito à informação impossibilita o recebi- 
mento de dados que permitam a compreensão da totalidade e a liberdade de conhecimento" (p. 36), e a imprensa, que, para o autor, "se constitui no mais eficiente meio para propagação de idéias e no principal agente orientador da opinião pública, já que transporta para o individual as verdades do coletivo" [sem grifo no original] (p. 37-38), deixa de cumprir uma de suas principais funções.

Além disso, os artigos publicados na RCB e na Veja, de modo geral, não são apresentados como documentos passíveis de análise, mas apreendidos como referências para justificar (negativa ou positivamente) as principais idéias do autor sobre uma série de acontecimentos, fatos e objetos. Por exemplo, o artigo Problemas estéticos na sociedade de massa (conclusão), de Ferreira Gullar, ${ }^{2}$ publicado na RCB dois anos depois do golpe militar, não é problematizado, mas confirma a tese de Stephanou sobre a censura e os meios de comunicação citada acima. Assim, as intenções do poeta e escritor, o suporte da publicação ou os leitores da revista não são sequer mencionados, quiçá problematizados.

Então, na prática, essa idéia sobre a informação e essa apreensão do documento contraria o que o autor defende em teoria, isto é, que

\begin{abstract}
o texto é uma narrativa intencional, uma produção de sentido, não um conjunto de verdades. A interpretação do conteúdo discursivo deve considerar contingências sociais e políticas do momento específico da sua produção e a interpretação individual de quem escreve. O jornalista procede a uma interpretação na qual a subjetividade está sempre presente, por isso é preciso enxergar no textos a sua carga de temporalidade. (...). É preciso ler os textos na sua complexidade, distinguindo entre o fato (o real acontecido) e a notícia (o real reconstruído) (p. 44).
\end{abstract}

Stephanou elabora, na segunda e terceira partes do livro, resumos do contexto político, econômico, social, artístico e cultural da época. Na segunda parte - $O$ contexto político e social da primeira fase do Regime Militar (1964/1968) -, o autor apresenta aos leitores, no plano político, as

2 GULLAR, Ferreira. Problemas estéticos na sociedade de massa (conclusão). Revista Civilização Brasileira, Rio de Janeiro, a. 1, n. 8, p. 243-249, jul. 1966. 
principais funções das Forças Armadas, da Doutrina de Segurança Nacional (DSN), da Escola Superior de Guerra (ESG), do Conselho de Segurança Nacional (CSN), dos Inquéritos Policiais Militares (IPMs), dos Atos Institucionais (AIs), da Constituição Brasileira de 1967, da Lei de Imprensa e dos Partidos Políticos (ARENA e MDB); no plano econômico, as características gerais do modelo de desenvolvimento associado ou dependente; e, no plano social, a estruturação dos movimentos de oposição ao regime militar, com destaque para a Igreja Católica e os movimentos operário e estudantil, entre outros.

Ainda nesta parte, Stephanou se utiliza, por exemplo, das memórias de Márcio Moreira Alves, publicadas em $1993,{ }^{3}$ e do artigo de Nelson Werneck Sodré, editado em 1965, ${ }^{4}$ para sustentar, respectivamente, suas teses sobre a DSN (p. 57) e os IPMs (p. 62). Agindo assim, o autor não distingue memória de história e reforça o discurso construído pelas esquerdas acerca dos instrumentos repressivos do regime militar. Discurso este que não é menos legítimo ou verdadeiro, mas que revela apenas uma interpretação circunstanciada da realidade. Isso não quer dizer que intencionamos relativizar ou justificar a violência dos instrumentos repressivos empregados pelos governos militares - entre os quais a censura -, mas identificar o local, o sujeito, a mensagem e o destino dessas idéias. Existe, dessa forma, uma intenção específica, um desejo subjacente à aparência e à superfície das palavras. Assim, devemos considerar, segundo Braudel, que o objeto do historiador está além da espuma das ondas do mar ou do brilho fosco dos vaga-lumes na escuridão.

Na terceira parte da obra - A combatividade e a militarização das artes -, Stephanou destaca a atuação de artistas e intelectuais na constituição do que se convencionou denominar "cultura de protesto", com destaque para os núcleos teatrais do eixo Rio-São Paulo, os festivais da canção, os filmes nacionais, entre outros. Assim, participaram dessa "cultura de protesto” não só o teatro, mas também a música, o cinema, as artes plásticas, a literatura, a imprensa, enfim, as produções artístico-culturais de cu-

3 ALVES, Márcio Moreira. 68 mudou o mundo. 2. ed. Rio de Janeiro: Nova Fronteira, 1993. $188 \mathrm{p}$.

4 SODRÉ, Nelson Werneck. História da nova história. Revista Civilização Brasileira, Rio de Janeiro, a. 1, n. 3, p. 27-40, jul. 1965. 
nho político dos anos de 1960. O autor considera então que "a mobilização dos intelectuais e a produção e circulação cultural de obras com forte conteúdo político foi a tônica dos anos 60” (p. 115). Não obstante, não podemos aleatoriamente destacar uma característica específica, definida sob o rótulo genérico de "político", para as artes brasileiras dos anos de 1960. Primeiro, porque não existe uma só arte ou um só artista e, segundo, porque o golpe militar e, desde então, as políticas públicas do regime militar interferiram na produção artístico-cultural, sobretudo pelo controle da circulação dos bens culturais no espaço público e da distribuição de verbas pelas agências de fomento. Não podemos, nesse sentido, ignorar as divergências e a diversidade das produções artístico-culturais anteriores e posteriores a 1964.

Com isso, concordamos com a afirmação de Stephanou sobre a participação intensa e vital dos atores, diretores, dramaturgos, produtores e núcleos teatrais, afinal, estes organizaram uma série de atos públicos de protesto (abaixo-assinados, cartas abertas, greves e passeatas) em oposição ao regime militar. Contudo, afirmar que "as pessoas iam ao teatro ou ao cinema como quem vai a uma manifestação política” (p. 116) é uma hipótese que merece mais atenção e cuidado. Por exemplo, quem são essas pessoas, quais são essas peças teatrais e filmes, quem as idealizou e produziu, enfim, delimitar esses espaços de resistência e protesto. Pois, configurado da maneira como supõe o autor, dá-nos a impressão de que havia uma homogeneidade entre tendências político-culturais diversas; e que todo o conjunto da sociedade, ainda nos anos de 1964 e 1968, estava contra o regime militar. Quando sabemos, por pesquisas já realizadas, que extratos da classe média, a princípio, se beneficiaram com o plano econômico adotado pelos governos militares e colaboraram, de diversas maneiras, com sua gerência. Assim, uma das funções do historiador é investigar as intenções dos documentos e não aderir às suas opiniões e conclusões indistintamente. Considerar, por exemplo, que

o documento não é inócuo. (...). O documento é uma coisa que fica, que dura, e o testemunho, o ensinamento (...) que ele traz devem ser em primeiro lugar analisados desmistificando-lhe o seu significado aparente. O documento é monumento. Resulta do esforço das sociedades históricas para se impor ao futuro voluntária ou involuntariamente - determina imagem de si 
próprias. No limite, não existe um documento-verdade. Todo documento é mentira. Cabe ao historiador não fazer o papel de ingênuo. (...). É preciso começar por desmontar, demolir esta montagem, desestruturar esta construção e analisar as condições de produção dos documentos-monumentos. ${ }^{5}$

Essa noção de documento/monumento pode e deve ser aplicada aos números (p. ex. as estatísticas), tão passíveis de manipulações quanto as palavras (p. ex. os artigos). No livro, Stephanou cita inúmeras estatísticas que não são questionadas e também não indica suas origens - por exemplo, da apresentação de peças nacionais no eixo Rio-São Paulo em 1964 (p. 132) ou da bilheteria do teatro brasileiro em 1966 (p. 133). E, ainda que discutisse ou indicasse a procedência dessas informações, essas estatísticas devem ser revistas pelos pesquisadores, pois sabemos que muitas delas são hipóteses ou aproximações realizadas ou publicadas ora pela imprensa, ora pelos protagonistas (militares ou civis). O (f)ato de reforçar ou ignorar determinada estatística/estimativa - de fonte (des)conhecida - está relacionado às preocupações de classes, grupos e indivíduos de "tornarem-se senhores da memória e do esquecimento”. ${ }^{6}$ Então, devemos nos perguntar: quais as intenções desses indivíduos e grupos mais visados pelo regime militar ao produzirem e publicarem determinada estimativa? Devemos confiar irrestritamente em estatísticas elaboradas e veiculadas por determinados grupos ou indivíduos, sejam estes de esquerda ou de direita, militar ou civil, censurado ou censor, torturado ou torturador?

Com essa preocupação estaríamos, então, trabalhando para desmistificar as construções da história e sobretudo da memória, pois, segundo Le Goff, “a memória, onde cresce a história, que por sua vez a alimenta, procura salvar o passado para servir o presente e o futuro. Devemos trabalhar de forma a que a memória coletiva sirva para a libertação e não para a servidão dos homens."

5 LE GOFF, Jacques. Prefácio; Memória. História e memória. Tradução: Bernardo Leitão et al. 4. ed. Campinas: Unicamp, 1996. 553 p. (Coleção Repertórios). Tradução de: Storia e memoria. p. 547-548.

6 Ibid., p. 426.

7 Ibid., p. 477. 
Na última parte do livro - A censura no Regime Militar: primeira fase (1964/1968) -, o autor evidencia diretamente o fenômeno da censura in loco: o organograma dos seus principais órgãos; a legislação revisada e instituída para regularizar a atividade da censura e a profissão do censor; a censura descentralizada nas superintendências regionais e centralizada na Divisão de Censura de Diversões Públicas (DCDP), do Departamento de Política Federal (DPF), do Ministério da Justiça (MJ); e, as estratégias utilizadas por artistas e intelectuais para desviar a atenção dos censores e não cair nas malhas da censura. Stephanou, então, comparando-a com os órgãos de informação do regime militar, constatou que

se 1964-1968 foi um período de laboratório para os órgãos de informação, também foi para a Censura. Os órgãos de informação e o SCDP passaram por um constante processo de modernização, principalmente através da aquisição de equipamentos mais eficientes e treinamento especializado. Os serviços de informação foram sendo centralizados, assim como a Censura. Ambos foram criando, também, ao longo do Regime Militar, um discurso de legitimação. E ambos tiveram cada vez mais ampliados seus campos de atuação e seus quadros de funcionários (p. 260).

De qualquer maneira, a centralização da censura em Brasília não resolveu de imediato os problemas que antes atingiam os órgãos estaduais, entre os quais podemos citar a subjetividade e o improviso que caracterizaram os primeiros pareceres efetuados pelos censores federais, posteriormente denominados técnicos da censura. E, por mais moderna e especializada, a DCDP nunca conseguiu, segundo Fico, acompanhar a evolução tecnológica da Rede Globo, por exemplo, forçando inclusive a emissora, em 1971, a doar um equipamento de vídeo e ceder operadores necessários para que a censura das novelas fosse realizada em Brasília e não nas dependências da empresa, situação esta que gerava constrangimento e hostilidade de ambos os lados. ${ }^{8}$

8 FICO, Carlos. "Prezada Censura”: cartas ao regime militar. Topoi, Rio de Janeiro, n. 5, p. 251-286, set. 2002. 
Ainda para fundamentar a tese central do livro, questionar as três fases tradicionais da censura (p. 13) e distanciar-se das pesquisas acadêmicas já realizadas, Stephanou afirma que

Muitos historiadores, sociólogos e jornalistas concordam no fato de que os governos de Castello Branco e Costa e Silva “censuraram menos”. Porém, não se pode considerar branda e assistemática uma censura que obstruiu ou retalhou qualquer produção mais claramente crítica/oposicionista, não se pode considerar amena ou reduzida uma censura que combinou supressão de obras com atos de terrorismo e pressão econômica, o que inclusive levou ao fechamento de diversas empresas de comunicação. Essa visão foi deformada, na verdade, porque a maioria dos estudos sobre censura se concentram na imprensa, e mais especificamente na imprensa escrita, justamente a menos visada neste período, em que a Censura se dedicou mais ao teatro e ao cinema, até porque a maioria dos jornais e revistas haviam apoiado o Movimento Militar de 64 (p. 291).

Considerando esse argumento, não entendemos por que então o autor elegeu como fontes historiográficas as revistas RCB e Veja e não os processos ou cartas do Serviço de Censura de Diversões Públicas (SCDP), por exemplo. Abordar a censura de “forma genérica” (p. 291) - isto é, não apenas centrada no SCDP - não justifica essa escolha, pelo contrário, a documentação produzida pelo SCDP deveria, pelo menos, ser uma das fontes eleitas. Desse modo, a censura analisada sob uma perspectiva "genérica” não exclui a necessidade de se consultar o material produzido pelos seus principais órgãos e instituições, o que, na dissertação de mestrado de Stephanou, parece não ter acontecido.

Essa escolha gerou uma série de controvérsias, por exemplo, a de afirmar que "o perigoso traduzia-se na existência de uma arte política, de uma forte cultura de oposição, um teatro conscientizador, literatura crítica, cinema de denúncia social, canção de protesto” (p. 15). Uma afirmativa dessas depende fundamentalmente da documentação consultada. Por razões que não devemos ignorar, uma parcela da imprensa, por exemplo, acentuou a ação da censura sobre essa cultura denominada de protesto. Por outro lado, uma análise investigativa e quantitativa 
do Fundo da DCDP ${ }^{9}$ - disponível à consulta pública no Arquivo Nacional no Distrito Federal desde 1996 - evidencia que a censura política não foi o forte desse órgão público, que, apesar de realizá-la, nunca se sentiu totalmente liberado para tanto. ${ }^{10}$ Daí a necessidade de se diferenciar (e não hierarquizar) a censura moral da política e a censura da imprensa da de diversões públicas, metodologia que não está completamente clara em Censura no regime militar e militarização das artes.

Insistimos nesse problema central da obra porque foi justamente isso que desencadeou uma série de controvérsias visíveis no decorrer do texto. E a justificativa dessa escolha, isto é, de que "a seleção estratégica de informações constrói uma determinada realidade, firma idéias, não podendo a censura, portanto, ser lida somente no que foi proibido, mas também no que foi reforçado, sistematicamente vinculado" (p. 37), apesar de não se efetivar no livro quando confrontamos a teoria com a prática, é um excelente recurso teórico-metológico, pois não é só o que foi censurado que permite analisar a ideologia do regime militar, mas também o que foi aceito e permitido. E é justamente nessa fronteira entre o proibido e o aprovado que devemos trabalhar daqui em diante.

9 OLIVEIRA, Eliane Braga de; RESENDE, Maria Esperança de. A censura de diversões públicas no Brasil durante o regime militar. Dimensões, Espírito Santo, v. 12, p. 150-161, jan./jun. 2001.

10 FICO, op. cit., p. 260. 